\title{
Hysteroscopy in the management of endometrial hyperplasia and cancer in reproductive aged women: new developments and current perspectives
}

\author{
Salvatore Giovanni Vitale ${ }^{1}$, Gaetano Riemma ${ }^{2}$ Jose Carugno ${ }^{3}$, Benito Chiofalo ${ }^{4}$, \\ George Angelos Vilos ${ }^{5}$, Stefano Cianci ${ }^{2}$, Mehmet Sukru Budak ${ }^{6}$, Bernardo Portugal Lasmar ${ }^{7}$ \\ Antonio Raffone ${ }^{8}$, Ilker Kahramanoglu'
}

${ }^{1}$ Obstetrics and Gynecology Unit, Department of General Surgery and Medical Surgical Specialties, University of Catania, Catania, Italy; ${ }^{2}$ Department of Woman, Child and General and Specialized Surgery, Obstetrics and Gynecology Unit, University of Campania 'Luigi Vanvitelli', Naples, Italy; ${ }^{3}$ Obstetrics, Gynecology and Reproductive Sciences Department, Minimally Invasive Gynecology Unit, Miller School of Medicine, University of Miami, Miami, FL, USA; ${ }^{4}$ Department of Experimental Clinical Oncology, IRCCS-Regina Elena National Cancer Institute, Rome, Italy; ${ }^{5}$ Department of Obstetrics and Gynecology, Western University, London, Ontario, Canada; ${ }^{6}$ Department of Obstetrics and Gynecology, Health Sciences University Diyarbakır Gazi Yaşargil Education and Research Hospital, Diyarbakır, Turkey; ${ }^{7}$ Department of Gynecological Endoscopy, Hospital Central Aristarcho Pessoa (HCAP-CBMERJ), Estacio de Sá University (UNESA), Rio de Janeiro, Brazil; ${ }^{8}$ Gynecology and Obstetrics Unit, Department of Neuroscience, Reproductive Sciences and Dentistry, School of Medicine, University of Naples Federico II, Naples, Italy; ${ }^{9}$ Department of Obstetrics and Gynecology, Division of Gynecologic Oncology, Cerrahpasa Faculty of Medicine, Istanbul University, Istanbul, Turkey

Contributions: (I) Conception and design: SG Vitale, G Riemma; (II) Administrative support: SG Vitale, J Carugno; (III) Provision of study materials or patients: G Riemma, B Chiofalo; (IV) Collection and assembly of data: G Riemma, B Chiofalo, S Cianci; (V) Data analysis and interpretation: G Riemma; (VI) Manuscript writing: All authors; (VII) Final approval of manuscript: All authors.

Correspondence to: Salvatore Giovanni Vitale, MD, PhD. Obstetrics and Gynecology Unit, Department of General Surgery and Medical Surgical Specialties, University of Catania, Via Santa Sofia 78, 95123 Catania, Italy. Email: sgvitale@unict.it; vitalesalvatore@hotmail.com.

\begin{abstract}
Over the last twenty years, the incidence of early endometrial cancer (EC) and atypical endometrial hyperplasia (AEH) among women of reproductive age is increasing rapidly, likely due to a combination of factors including increased prevalence of obesity and delayed of childbirths. Regarding preoperative diagnosis of endometrial neoplasia, it is still debated which is the most accurate and reliable method to obtain endometrial histopathological samples with fractional dilatation and curettage (D\&C) having been considered, for a long time, as the method of choice. Nowadays, the advent of in-office endometrial biopsy with or without hysteroscopy has radically changed the approach, giving the opportunity to perform the endometrial biopsy under direct visualization. However, the lack of agreement about its diagnostic accuracy is still relevant. Since a significant number of women with AEH and/or EC are of childbearing age, a fertility-sparing diagnostic and therapeutic approach should be considered in all cases. The feasibility, safety and efficacy of fertility-sparing strategies involving hysteroscopic focal resections in conjunction with hormonal therapies have been evaluated and beneficial effects have been confirmed in several studies and one meta-analysis. Both local and systemic administration of hormonal therapies are currently used. Oral progestin, including medroxyprogesterone acetate (MPA) and megestrol acetate, are the most commonly used therapies. Nowadays, new therapeutic approaches, such as levonorgestrel intrauterine systems (LNG-IUS), gonadotropin-releasing hormone (GnRH) agonists, combined megestrol acetate and metformin, and other combinations of therapies are also used as first line therapies or after the hysteroscopic resection of the lesion. However, it is still unclear which approach provides higher clinical response with lower relapse rate, in addition to preserving fertility in women desiring to conceive. The aim of this narrative review is to summarize the available evidence regarding the evaluation and management with fertility-sparing treatments options of women with AEC and EC.
\end{abstract}

Keywords: Hysteroscopy; endometrial carcinoma; endometrial atypical hyperplasia; fertility-sparing; infertility 
Submitted May 16, 2020. Accepted for publication Jul 06, 2020.

doi: $10.21037 /$ tcr-20-2092

View this article at: http://dx.doi.org/10.21037/tcr-20-2092

\section{Introduction}

Endometrial hyperplasia (EH) is characterized by excessive proliferation of endometrial glands of irregular size and shape (1). In 2014, the World Health Organization (WHO) revised the original classification of $\mathrm{EH}$ by eliminating the sub-classification of simple and complex hyperplasia $(\mathrm{SH}, \mathrm{CH})$ and proposed a classification into non atypical endometrial hyperplasia (NAH) and atypical endometrial hyperplasia $(\mathrm{AEH})$, which differentiates between premalignant and benign $\mathrm{EH}$ based on the presence of cytologic atypia (2). On the basis of this classification, nuclear atypia is a more reliable indicator of progression to endometrial carcinoma than is architectural abnormality (3) and it correlates with the response to progestin therapy (4). NAH progresses into EC in less than $5 \%$ of the cases. Therefore, it could be treated conservatively as a benign condition (5).

$\mathrm{AEH}$ is defined as glands that exhibit various degrees of nuclear atypia and loss of polarity and, if untreated, it may progress to or co-exist with endometrioid endometrial adenocarcinoma (EC) in $20 \%$ to $50 \%$ of cases (6). Other features, rather than nuclear atypia, may be used to classify endometrial hyperplasia as precancerous; these features are defined as endometrial intraepithelial neoplasia (EIN) criteria and classify endometrial hyperplasia in benign or EIN (7). In addition, WHO and EIN criteria might also be integrated in order to obtain a more tailored risk stratification of endometrial hyperplasia (8). The risk of $\mathrm{AEH}$ progressing to $\mathrm{EC}$ is related to the presence and severity of cytologic atypia $(8,9)$. Both AEH and EC are the consequence of an increased estrogens concentration, unopposed by progesterone that causes proliferative glandular epithelial changes (10-12).

$\mathrm{EC}$ is the most frequent gynecological neoplasm in developed countries. It is the fourth most common cancer in women regardless of their ethnicity, with a reported incidence of about $24 / 100,000$ women. Over $80 \%$ of ECs are reported as well/moderately differentiated endometrioid adenocarcinomas (13). These are strongly related to a prolonged and unopposed hyper-estrogenic state. A minor number of ECs had different histotype rather than endometrioid, it is related to a different and lesser-known etiopathology, and it has a worse prognosis compared to the endometrioid histotype $(14,15)$.

For many decades, one of the diagnostic methods for $\mathrm{EC}$ and $\mathrm{AEH}$ has been the traditional dilatation and curettage (D\&C) (16). However, blind sampling techniques show low specificity for preneoplastic and neoplastic endometrial diseases, as well as high cost-effectiveness (17). For this reason, D\&C has been gradually replaced by office endometrial biopsy with or without concomitant hysteroscopic evaluation of the uterine cavity (18). Studies comparing D\&C with hysteroscopically-guided endometrial biopsy have demonstrated that hysteroscopy is a less risky procedure with higher diagnostic accuracy than D\&C (19-21). Therefore, hysteroscopy is considered the gold standard in the diagnosis of endometrial neoplasia: it allows a clear visualization of the uterine cavity and focal lesions, which can be biopsied and/or completely removed under direct visualization.

Rather than D\&C, other blind (without direct visualization of the uterine cavity) techniques are still used in daily practice for retrieving endometrial samples. Between these sampling techniques, diagnostic accuracy of Pipelle biopsy was reported superior to D\&C. However, failure to get samples reduced its reliability, emphasizing the role of hysteroscopic targeted biopsy (22).

In addition to evaluating the endometrium and the endometrial cavity, clinical practice guidelines also recommend further assessment of potential myometrial invasion and the presence of coexistent ovarian cancer using imaging such as pelvic ultrasonography or magnetic resonance imaging (MRI) and even laparoscopy if deemed necessary $(23,24)$. In such a scenario, the use of PET-CT scan could help the gynecologist to choose the adequate diagnostic algorithm in the diagnostic workup of intermediate and high-risk EC, in order to choose between sentinel lymph node evaluation or pelvic/paraaortic lymphadenectomy in accordance to lymph node positivity at PET-CT scan $(25,26)$.

In clinical practice, baseline differences concerning obesity, parity, characteristics of AUB and intracavitary tumor growth could be found between pre- and postmenopausal EC (27).

A 2019 meta-analysis reported that the assessment of EC invasion was heterogeneous among various diagnostic 
techniques. In addition, the presence of an International Federation of Gynecology and Obstetrics (FIGO) stage 1, grade 1 , coexistent ovarian cancer together with $\mathrm{EC}$ was up to $23 \%$ (28).

As stated by the National Comprehensive Cancer Network (NCCN) consensus, reference standard of treatment for FIGO stage 1, grade $1 \mathrm{EC}$ is total hysterectomy with bilateral salpingo-oophorectomy (TH/ BSO) (13). However, such approach in young women who desires future fertility is unwanted. Therefore, in a selected group of patients who desire to preserve their fertility, a conservative treatment could be performed followed by subsequent TH/BSO after completing childbearing (23).

Such an approach has become crucial for childbearing women, while the actual modus-operandi, including major surgery, still remains the standard approach in elder women (29).

For this reason, hysteroscopy is gaining a pivotal role not only for the diagnosis, but also for the treatment of women with $\mathrm{AEH}$ and EC desiring fertility-sparing therapeutic options.

\section{Hysteroscopy in the evaluation of fertile women with AEH and EC}

The prevalence of $\mathrm{AEH}$ and $\mathrm{EC}$ in women of reproductive age showed a dramatic increase during the last few decades (30). Likely reasons for the early development of these endometrial diseases are the increased rate of obesity and the tendency to defer the first pregnancy, as well as a decreased number of childbirths (31). In fact, risk factors for AEH and EC can be subdivided in two main categories. The first category are endogenous factors, such as ovulatory disorders, obesity, polycystic ovarian syndrome (PCOS), family history of some adenocarcinomas and age (32). The second involves exogenous factors, such as exposure to unopposed estrogen (33). Although breast cancer also remains in the risk category for EC, tamoxifen therapy, which is used as an adjuvant therapy for breast cancer, is no longer considered a risk factor (34). It has also been reported that in reproductive-aged women, a decrease in progesterone level during the monthly luteal phase is associated with an uncontrolled proliferation and differentiation of the endometrium, which favor the proliferation of endometrial hyperplasia and EC $(35,36)$.

Therefore, the prolonged and unopposed estrogen stimulation of the endometrium that is associated with anovulation, is considered an underlined condition for an increased risk for EC. For this reason, anovulatory infertility is a risk factor for $\mathrm{AEH}$ and EC. Moreover, chronic anovulation, which is a common finding in women with PCOS, increases in almost three times risk of developing endometrial neoplasms (37).

Some patients undergoing infertility treatments may require the use of anti-estrogen drugs such as an aromatase inhibitor or clomiphene citrate in order to induce ovulation. The advantages of using these medications over recombinant follicle-stimulating hormone ( $\mathrm{rFSH}$ ) or human chorionic gonadotropin (hCG) may be to reduce the incidence of ovarian hyperstimulation (38). Calderon-Margalit et al. reported a statistically significant increased risk of endometrial carcinoma after exposure to clomiphene citrate. In addition, the use of treatments for infertility was higher in the EC/AEH group than in the not atypical EH group (39). These treatments often deliver an increased and unopposed elevation of estradiol over the physiologic level. Taken together, these exogenous risk factors may lead to EH. The association between the use of clomiphene citrate and an increased EC risk was also reported by Althuis et al. (40).

In addition, endometrial neoplasms are associated with other pathologies that have a significant impact on female fertility, such as moderate or severe intrauterine or cervical-isthmic adhesions (41). Moreover, in women with endometrial hyperplasia the prevalence of chronic endometritis was reported to be up to 50\% (42).

In order to potentially identify patients with $\mathrm{EH}$ more at risk for EC, some researchers have proposed that the measurement of relative telomere length in cell free DNA might be a potentially outstanding diagnostic tool; although promising, data are still scarce to validate its accuracy (43).

Both $\mathrm{AEH}$ and EC in reproductive age women, are most commonly diagnosed during the evaluation of abnormal uterine bleeding (AUB) (44). Moreover, the presence of large endometrial polyps $(>1.5 \mathrm{~cm})$ has been significantly correlated with higher rates of AEH also in premenopausal asymptomatic women (45). Suspicion of endometrial pathology should be raised when the endometrial thickness on vaginal ultrasound exceeds $16 \mathrm{~mm}$ in premenopausal women; however, the accuracy of ultrasound in premenopausal women is limited, as it seems to be unable to discriminate between physiologic and pathologic endometrial thickness (46).

Since there is no consensus about a discriminatory sonographic endometrial thickness before proceeding with a more invasive diagnostic procedure, hysteroscopy 
is considered as the reference standard for diagnosis and, in some cases, also for treatment (see and treat) (24). Technological innovations in the field of hysteroscopy have improved the feasibility and applications of surgical hysteroscopy in an outpatient setting $(47,48)$. However, it is recommended to perform a diagnostic hysteroscopy when in the presence of suspected endometrial malignancy during ultrasonographic examination. On the other hand, the value of hysteroscopy alone in the diagnosis of EH and EC is still debated (49,50). Several studies have reported its superiority to $\mathrm{D} \& \mathrm{C}$ with a high sensitivity of in-office hysteroscopy combined with targeted biopsies in diagnosing $\mathrm{AEH}$ and EC. The main morphological hysteroscopic parameters that may be used as indicators of AEH are local or diffuse endometrial thickening with papillary or polypoid appearance, abnormal vascular patterns, presence of glandular cysts and glandular outlets demonstrating abnormal architectural features $(51,52)$. However, these features have not been defined based on controlled randomized clinical trials (RCTs) studies, but retrieved from large retrospective series $(53,54)$. The accuracy of hysteroscopy in diagnosing AEH and/or EC in women with AUB has been evaluated in a meta-analysis that reported a sensitivity of no more than $78 \%$ in the diagnosis of AEH and a higher accuracy to detect EC (55). The visual diagnosis of $\mathrm{EC}$ is based on the presence of a gross distortion of the endometrial cavity, as a result of a nodular, polypoid, papillary, or mixed pattern of neoplastic growth. Focal necrosis, microcalcifications, friable consistency, and atypical vessels are other characteristics associated with EC that could be easily detected by hysteroscopic inspection (56).

An additional critical role of hysteroscopy is to determine the extension of EC into the cervical canal; an important factor for the decision-making process which cannot be determined by office endometrial biopsy and could only be potentially determined by the traditional fractional D\&C. In such cases (FIGO stage II disease), a fertility-sparing approach should not be considered for these women. However, the definitive diagnosis of both $\mathrm{EH}$ and $\mathrm{EC}$ remains a core competence of the pathologist, because it requires histological examination of endometrial biopsies $(57,58)$. Diagnostic accuracy of histological examination may be improved by immunohistochemical markers, which may help in differentiating between benign $\mathrm{EH}, \mathrm{AEH}$ and EC $(59,60)$. In particular, paired box 2 protein (PAX2), loss of B - cell lymphoma 2 (Bcl-2), betacatenin, and AT-rich interaction domain 1A (ARID1A) appear as the most accurate immunohistochemical markers in this field (59).

\section{Hysteroscopic resection plus adjuvant hormone treatment for AEH and EC}

$\mathrm{EH}$ without atypia has a risk of progression to EC less than $5 \%$, and the majority of cases regress spontaneously during the follow-up (61). Progesterone treatment is indicated in women who fail to regress following observation alone, or in symptomatic women $(24,58)$. In the presence of $\mathrm{AEH}$ and FIGO stage 1 , grade $1 \mathrm{EC}$ the gold standard treatment is TH-BSO $(23,62)$. However, fertility-sparing treatment could be offered to women with desire to retain their fertility who are diagnosed with $\mathrm{AEH}$ and/or endometrioid, FIGO stage IA, grade $1 \mathrm{EC}$ without myometrial or lymph/ vascular space invasion $(23,63)$.

Before starting a fertility-sparing treatment, it is recommended to counsel women with AEH about the risks of coexisting EC or subsequent progression of $\mathrm{AEH}$ to EC despite appropriate treatment. Moreover, women should be counselled about available pretreatment investigations in order to rule out invasive $\mathrm{EC}$ or coexisting ovarian cancer. In this scenario, it is crucial to ensure the absence of metastatic disease or an adnexal mass on imaging studies (ultrasonography, MRI or CT scan). Therefore, appropriate informed consent should be obtained, explaining all potential risk and benefits that might occur while undertaking a fertility-sparing treatment $(35,36)$. In addition, since the goal of fertility-sparing treatment is conception, women with contraindications to receive hormone therapy, or having other causes of infertility such as fallopian tube pathology or male factor, should be carefully counselled by the clinician before proceeding further (64). In the next future, a panel of immunohistochemical markers might be useful in order to predict the response to fertility-sparing treatment of $\mathrm{AEH}$ and EC $(12,15)$. However, patients need to understand that once the reproductive desire is satisfied, TH-BSO should be undertaken in view of the high risk of disease relapse (58).

The fertility-sparing treatment options are hormone therapy, hysteroscopic resection or combined treatment. Hormonal therapies include oral progestins (such as megestrol acetate or medroxyprogesterone acetate) or levonorgestrel-releasing intrauterine system (LNG-IUS) $(65,66)$.

Both hormonal therapies can be used in combination with hysteroscopic resection, a conservative surgical 


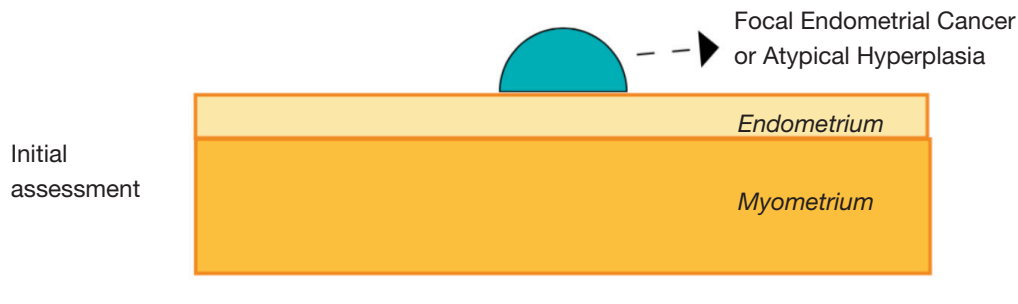

Step 1

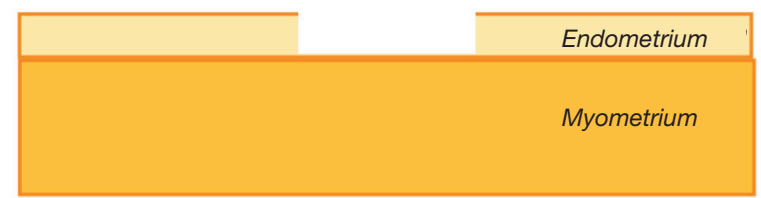

First Histological

Sample

Step 2

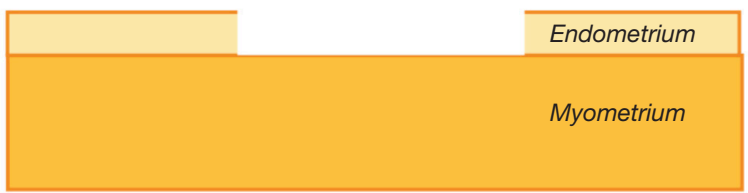

Second Histological

Sample

Step 3

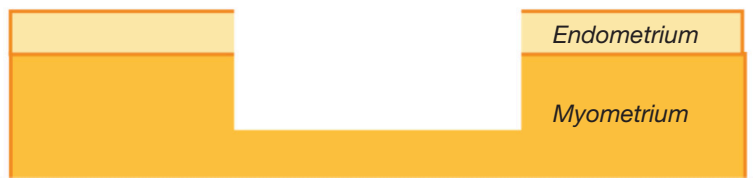

Third Histological

Sample

Figure 1 Schematic diagram of hysteroscopic focal resection for endometrial atypical hyperplasia and carcinoma, initially described by Mazzon et al.

approach, firstly described by Mazzon et al. in 2005 (67). This technique requires the removal of the exophytic heteroplastic lesion (first histopathological sample), followed by resection of the surrounding endometrium (between 4 and $5 \mathrm{~mm}$ ) at each side of the lesion (second histopathological sample) and the removal of the myometrial layer beneath the pathology for 3 to $4 \mathrm{~mm}$ (Third histopathological sample) (Figure 1).

A 2017 meta-analysis showed that hysteroscopic resection followed by hormonal therapy for well differentiated early-stage EC and AEH, achieved a significantly higher regression $(98.06 \%$ vs. $77.20 \%)$ and live birth rate $(52.57 \%$ vs. $33.38 \%)$ and a lower recurrence rate (4.79\% vs. $32.17 \%)$ compared with oral progestogens alone. Moreover, the live birth rate after hysteroscopic treatment in combination with progestin therapy was also significantly higher than the LNG-IUS alone ( $52.57 \%$ vs. $18.09 \%$ ), with no statistical difference in regression $(98.06 \% v s .94 .24 \%)$ and recurrence rates (4.79\% vs. 3.90\%) (68). Several previous studies have also shown similar results (69-71). Moreover, concerning EC recurrence, a recent research found that the presence of glandular cells at cervical smear, together with cervical stromal invasion, were significantly related to an additional risk for recurrence (72). In a 2010 meta-analysis, the regression rate reported for hormonal therapy alone, surgery alone, and the combination of both therapies were $49.6 \%, 75 \%$, and $100 \%$, respectively (73). A 2019 study reported that the combined treatment with hysteroscopic endometrial focal resection followed by the insertion of a LNG-IUS for 12 months, is a feasible and effective approach in the fertility-sparing treatment of atypical EH and EC. Women who aim to preserve fertility have similar oncologic, reproductive and obstetric outcomes when progestin-based treatments were compared. However, such findings should be further assessed by larger randomized controlled trials (74). Regardless of the fertility sparing approach, the reproductive outcomes are encouraging: after progesterone therapy, $41.2 \%$ of patients with $\mathrm{AEH}$ and $34.8 \%$ of patients with EC became pregnant (75). The reported pregnancy rates after hysteroscopic resection 
range from $25 \%$ to $100 \%$ (76), with a live birth rate of $28 \%$. Gallos et al. published a meta-analysis in which the live birth rate was higher in women who underwent assisted reproduction techniques (ART) than women who conceived spontaneously (39\% vs. 15\%) (77).

Additional studies have explored the combined treatment with gonadotropin-releasing hormone $(\mathrm{GnRH})$ agonist for 3 months after focal hysteroscopic resection. Such combination has been validated over time for AEH/EIN and $\mathrm{EC}$, and it is frequently offered to young women. However, as for all other fertility-sparing treatments, a strict follow-up is mandatory and post-delivery hysterectomy should be recommended (78,79).

Most patients with $\mathrm{AEH}$ and EC, eligible for fertilitysparing treatments, share a background of obesity, peripheral insulin resistance and abnormal glucose tolerance, that could also be enhanced by coexisting PCOS; all of which can be treated with metformin (80). Recently, the administration of metformin has also been used in this clinical context. In fact, several in vitro and in vivo studies have investigated the efficacy of metformin in the management of $\mathrm{EC}$ and $\mathrm{AEH}(81,82)$. Up to date, the efficacy of combining metformin with medroxyprogesterone acetate has been reported in a single-phase II study as a fertility-sparing treatment in patients with $\mathrm{AEH}$ or $\mathrm{EC}$, in addition to improving their metabolic profile. Nonetheless, its supplementation might improve the long-term oncological outcome of these patients (82).

A study by Yang et al. reported that, in patients with $\mathrm{AEH}$, metformin plus megestrol acetate was associated with an increased rate of complete response after 16 weeks of treatment when compared to megestrol acetate alone. In addition, such improvement was also statistically significant in young women without obesity or insulin-resistance, and in women with $\mathrm{AEH}$ without hypertension or diabetes. Moreover, safety and feasibility were confirmed, with no side or adverse effects in the metformin group. The improved clinical response using metformin could be attributed to both an enhanced efficacy of the progestin supplement as well as a direct or indirect anti-proliferative function of metformin (82). To date, several clinical trials utilizing combinations of progestins and metformin as a fertility-sparing treatment of $\mathrm{AEH}$ and $\mathrm{EC}$ are ongoing. Lastly, the possibility of adding a progestin plus metformin after hysteroscopic resection of AEH or EC would also be an interesting proposal to investigate in well-designed prospective studies in the next future.

Regardless of the treatment considered for a given patient, the ESGO guidelines recommend that a prior consultation with a fertility expert should be obtained because a significant number of young patients with AEH and/or EC have also infertility, PCOS, and/or obesity $(83,84)$. In our practice, we also strongly recommend a consultation with a gynecological oncologist and a dietician prior to offering a fertility sparing therapy to women with $\mathrm{AEH}$ and/or EC. In a fertility sparing approach, a multidisciplinary team, including a psychological support for the woman, is essential. Anxiety, depression and fear could harass the patient during the therapeutic path; enhancing her quality of life through a psychological support is crucial in order to improve the efficacy of the treatment (85-87).

Concerning follow-up, it should be individualized to each patient, taking into account baseline risk factors, associated symptoms and response to treatment; the frequency of the endometrial sampling remains a topic of debate, but current guidelines recommend uterine re-evaluation by hysteroscopy and biopsy every 3-6 months (88).

Based on limited available data, a 2019 meta-analysis reported that a comprehensive hysteroscopic intracavitary evaluation, followed by complete resection of the lesion plus progestin therapy in young women with EAH and $\mathrm{EC}$ achieves a complete resolution of the disease in an average of 6 months, regardless of the type of hormone therapy used. Moreover, a BMI lower than $25 \mathrm{~kg} / \mathrm{m}^{2}$ and initial lesion size not greater than $2 \mathrm{~cm}$ were found to be associated with a shorter duration of treatment to achieve a complete response (89).

Considering available scientific evidence, there is no consistent conclusions about which fertility treatment option is most advantageous after conservative treatment of AEH or EC, although it has been suggested that ART is especially beneficial for such patients $(90,91)$. Moreover, there is no established standard for treatment and further studies are needed to better evaluate hysteroscopic resection with or without hormonal therapy, as well as the combination with metformin, or frequency and length of follow-up (92).

Lastly, at least two other considerations about hysteroscopic resection of AEH and EC should be noted. First, it may be difficult to identify and delineate the extend of $\mathrm{AEH}$ and $\mathrm{EC}$ to achieve a complete hysteroscopic focal resection. In fact, these lesions may be widely spread and involve most, if not all, of the endometrium. Moreover, they lack of specific hysteroscopic features which makes it difficult to recognize especially when the procedure is 
performed by inexperienced hysteroscopists (93).

The second consideration regards whether hysteroscopic surgery increases the risk of positive peritoneal cytology in women with EC. Although the issue remains unresolved, positive peritoneal cytology associated with EC has not been shown to worsen the clinical outcomes and patient prognosis. Vilos et al. reported that resectoscopic surgery did not adversely affect the 5-year survival rate and the long-term prognosis in 14 women with EC (94).

\section{Conclusions}

Office hysteroscopy with endometrial biopsy under direct visualization appears as the best approach for the diagnosis of benign $\mathrm{EH}, \mathrm{AEH}$ and $\mathrm{EC}$; however, a standardisation of diagnostic hysteroscopic features of these lesions is required.

Hysteroscopic resection followed by LNG-IUS insertion or oral progestins with or without metformin, or $\mathrm{GnRH}$ agonists, are effective fertility-sparing treatment options for women with $\mathrm{AEH}$ and/or EC who desire future fertility. However, it is recommended to evaluate the myometrial invasion and the possibility of a coexisting ovarian malignancy prior to considering fertility sparing therapy.

\section{Acknowledgments}

Funding: None.

\section{Footnote}

Provenance and Peer Review: This article was commissioned by the Guest Editor (Antonio Simone Laganà) for the series "Endometrial Cancer" published in Translational Cancer Research. The article was sent for external peer review organized by the Guest Editor and the editorial office.

Conflicts of Interest: All authors have completed the ICMJE uniform disclosure form (available at http://dx.doi. org/10.21037/tcr-20-2092). The series "Endometrial Cancer" was commissioned by the editorial office without any funding or sponsorship. The authors have no other conflicts of interest to declare.

Ethical Statement: The authors are accountable for all aspects of the work in ensuring that questions related to the accuracy or integrity of any part of the work are appropriately investigated and resolved.

Open Access Statement: This is an Open Access article distributed in accordance with the Creative Commons Attribution-NonCommercial-NoDerivs 4.0 International License (CC BY-NC-ND 4.0), which permits the noncommercial replication and distribution of the article with the strict proviso that no changes or edits are made and the original work is properly cited (including links to both the formal publication through the relevant DOI and the license). See: https://creativecommons.org/licenses/by-nc-nd/4.0/.

\section{References}

1. Kurman RJ. WHO classification of tumours of female reproductive organs. Fourth edition. World Health Organization Classification of Tumours.

2. Carcangiu ML, Kurman RJ, Carcangiu ML, et al. WHO Classification of Tumours of Female Reproductive Organs. 4th ed. World Health Organization Classification of Tumours. Lyon: International Agency for Research on Cancer; 2014.

3. Sanderson PA, Critchley HO, Williams AR, et al. New concepts for an old problem: the diagnosis of endometrial hyperplasia. Hum Reprod Update 2017;23:232-54.

4. Ferenczy A, Gelfand M. The biologic significance of cytologic atypia in progestogen-treated endometrial hyperplasia. Am J Obstet Gynecol 1989;160:126-31.

5. Vilos GA, Oraif A, Vilos AG, et al. Long-term clinical outcomes following resectoscopic endometrial ablation of non-atypical endometrial hyperplasia in women with abnormal uterine bleeding. J Minim Invasive Gynecol 2015;22:66-77.

6. Salman MC, Usubutun A, Boynukalin K, et al. Comparison of $\mathrm{WHO}$ and endometrial intraepithelial neoplasia classifications in predicting the presence of coexistent malignancy in endometrial hyperplasia. J Gynecol Oncol 2010;21:97-101.

7. Sobczuk K, Sobczuk A. New classification system of endometrial hyperplasia WHO 2014 and its clinical implications. Prz Menopauzalny 2017;16:107-11.

8. Raffone A, Travaglino A, Saccone G, et al. Endometrial hyperplasia and progression to cancer: which classification system stratifies the risk better? A systematic review and meta-analysis. Arch Gynecol Obstet 2019;299:1233-42.

9. Hunter JE, Tritz DE, Howell MG, et al. The prognostic and therapeutic implications of cytologic atypia in 
patients with endometrial hyperplasia. Gynecol Oncol 1994;55:66-71.

10. Lacey JV, Chia VM. Endometrial hyperplasia and the risk of progression to carcinoma. Maturitas 2009;63:39-44.

11. Sherman ME. Theories of endometrial carcinogenesis: a multidisciplinary approach. Mod Pathol 2000;13:295-308.

12. Raffone A, Travaglino A, Saccone G, et al. Should progesterone and estrogen receptors be assessed for predicting the response to conservative treatment of endometrial hyperplasia and cancer? A systematic review and meta-analysis. Acta Obstet Gynecol Scand 2019;98:976-87.

13. Gadducci A, Spirito N, Baroni E, et al. The fertilitysparing treatment in patients with endometrial atypical hyperplasia and early endometrial cancer: a debated therapeutic option. Gynecol Endocrinol 2009;25:683-91.

14. Gueli Alletti S, Cianci S, Perrone E, et al. Technological innovation and personalized surgical treatment for early-stage endometrial cancer patients: A prospective multicenter Italian experience to evaluate the novel percutaneous approach. Eur J Obstet Gynecol Reprod Biol 2019;234:218-22.

15. Raffone A, Travaglino A, Mascolo M, et al. Predictive accuracy of hormone receptors in conservatively treated endometrial hyperplasia and early endometrioid carcinoma. Acta Obstet Gynecol Scand 2020;99:140.

16. Sanam M, Majid MM. Comparison the Diagnostic Value of Dilatation and Curettage Versus Endometrial Biopsy by Pipelle--a Clinical Trial. Asian Pac J Cancer Prev 2015;16:4971-5.

17. Palmer JE, Perunovic B, Tidy JA. Endometrial hyperplasia. Obstet Gynaecol 2008;10:211-6.

18. Vitale SG. The Biopsy Snake Grasper Sec. VITALE: A New Tool for Office Hysteroscopy. J Minim Invasive Gynecol 2020;271414-6.

19. Bedner R, Rzepka-Gorska I. Hysteroscopy with directed biopsy versus dilatation and curettage for the diagnosis of endometrial hyperplasia and cancer in perimenopausal women. Eur J Gynaecol Oncol 2007;28:400-2.

20. Ceci O, Bettocchi S, Pellegrino A, et al. Comparison of hysteroscopic and hysterectomy findings for assessing the diagnostic accuracy of office hysteroscopy. Fertil Steril 2002;78:628-31.

21. Loffer FD. The Time Has Come to Quit Relying on a Blind Endometrial Biopsy or Dilation and Curettage to Rule Out Malignant Endometrial Changes. J Minim Invasive Gynecol 2019;26:1207-8.

22. Terzic MM, Aimagambetova G, Terzic S, et al. Current role of Pipelle endometrial sampling in early diagnosis of endometrial cancer. Transl Cancer Res 2020. doi: 10.21037/tcr.2020.04.20.

23. Koh WJ, Abu-Rustum NR, Bean S, et al. Uterine Neoplasms, Version 1.2018, NCCN Clinical Practice Guidelines in Oncology. J Natl Compr Canc Netw 2018;16:170-99.

24. Colombo N, Creutzberg C, Amant F, et al. ESMOESGO-ESTRO consensus conference on endometrial cancer: Diagnosis, treatment and follow-up. Radiother Oncol 2015;117:559-81.

25. Franchi M, Garzon S, Zorzato PC, et al. PET-CT scan in the preoperative workup of early stage intermediate- and high-risk endometrial cancer. Minim Invasive Ther Allied Technol 2020;29:232-9.

26. Cignini P, Vitale SG, Laganà AS, et al. Preoperative workup for definition of lymph node risk involvement in early stage endometrial cancer: 5-year follow-up. Updates Surg 2017;69:75-82.

27. Andrijašević S, Dotlić J, Arsenović N, et al. Differences in endometrial carcinoma presentations and characteristics in pre- and postmenopausal women. Srp Arh Celok Lek 2019;147:692-8.

28. Guillon S, Popescu N, Phelippeau J, et al. A systematic review and meta-analysis of prognostic factors for remission in fertility-sparing management of endometrial atypical hyperplasia and adenocarcinoma. Int J Gynaecol Obstet 2019;146:277-88.

29. Vitale SG, Capriglione S, Zito G, et al. Management of endometrial, ovarian and cervical cancer in the elderly: current approach to a challenging condition. Arch Gynecol Obstet 2019;299:299-315.

30. Gueli Alletti S, Rossitto C, Cianci S, et al. Telelap ALF-X vs Standard Laparoscopy for the Treatment of Early-Stage Endometrial Cancer: A Single-Institution Retrospective Cohort Study. J Minim Invasive Gynecol 2016;23:378-83.

31. Nagle CM, Marquart L, Bain CJ, et al. Impact of weight change and weight cycling on risk of different subtypes of endometrial cancer. Eur J Cancer 2013;49:2717-26.

32. Ricci E, Moroni S, Parazzini F, et al. Risk factors for endometrial hyperplasia: results from a case-control study. Int J Gynecol Cancer 2002;12:257-60.

33. Key TJ, Pike MC. The dose-effect relationship between 'unopposed' oestrogens and endometrial mitotic rate: its central role in explaining and predicting endometrial cancer risk. Br J Cancer 1988;57:205-12.

34. Chiofalo B, Mazzon I, Di Angelo Antonio S, et al. Hysteroscopic Evaluation of Endometrial Changes 
in Breast Cancer Women with or without Hormone Therapies: Results from a Large Multicenter Cohort Study. J Minim Invasive Gynecol 2020;27:832-9.

35. Burke WM, Orr J, Leitao M, et al. Endometrial cancer: a review and current management strategies: part II. Gynecol Oncol 2014;134:393-402.

36. Burke WM, Orr J, Leitao M, et al. Endometrial cancer: a review and current management strategies: part I. Gynecol Oncol 2014;134:385-92.

37. Kuribayashi Y, Nakagawa K, Sugiyama R, et al. Frequency of endometrial cancer and atypical hyperplasia in infertile women undergoing hysteroscopic polypectomy. J Obstet Gynaecol Res 2017;43:1465-71.

38. Lunenfeld B, Bilger W, Longobardi S, et al. The Development of Gonadotropins for Clinical Use in the Treatment of Infertility. Front Endocrinol (Lausanne) 2019;10:429.

39. Calderon-Margalit R, Friedlander Y, Yanetz R, et al. Cancer risk after exposure to treatments for ovulation induction. Am J Epidemiol 2009;169:365-75.

40. Althuis MD, Moghissi KS, Westhoff CL, et al. Uterine cancer after use of clomiphene citrate to induce ovulation. Am J Epidemiol 2005;161:607-15.

41. Chiofalo B, Palmara V, Vilos GA, et al. Reproductive outcomes of infertile women undergoing "see and treat" office hysteroscopy: a retrospective observational study. Minim Invasive Ther Allied Technol 2019. [Epub ahead of print].

42. Song D, Feng X, Zhang Q, et al. Prevalence and confounders of chronic endometritis in premenopausal women with abnormal bleeding or reproductive failure. Reprod Biomed Online 2018;36:78-83.

43. Benati M, Montagnana M, Danese E, et al. Aberrant Telomere Length in Circulating Cell-Free DNA as Possible Blood Biomarker with High Diagnostic Performance in Endometrial Cancer. Pathol Oncol Res 2020;26:2281-9.

44. Fraser IS, Critchley HO, Munro MG, et al. A process designed to lead to international agreement on terminologies and definitions used to describe abnormalities of menstrual bleeding. Fertil Steril 2007;87:466-76.

45. Lasmar BP, Lasmar RB. Endometrial polyp size and polyp hyperplasia. Int J Gynaecol Obstet 2013;123:236-9.

46. Mahajan NN, Mahajan K, Soni R. Endometrial thickness screening in premenopausal women with abnormal uterine bleeding. J Obstet Gynaecol Res 2007;33:886; author reply 7 .
47. Vitale SG, Bruni S, Chiofalo B, et al. Updates in office hysteroscopy: a practical decalogue to perform a correct procedure. Updates Surg 2020;72:967-76.

48. Riemma G, Schiattarella A, Colacurci N, et al. Pharmacological and non-pharmacological pain relief for office hysteroscopy: an up-to-date review. Climacteric 2020;23:376-83.

49. Gkrozou F, Dimakopoulos G, Vrekoussis T, et al. Hysteroscopy in women with abnormal uterine bleeding: a meta-analysis on four major endometrial pathologies. Arch Gynecol Obstet 2015;291:1347-54.

50. De Franciscis P, Riemma G, Schiattarella A, et al. Concordance between the Hysteroscopic Diagnosis of Endometrial Hyperplasia and Histopathological Examination. Diagnostics (Basel) 2019;9:142.

51. Garuti G, Mirra M, Luerti M. Hysteroscopic view in atypical endometrial hyperplasias: A correlation with pathologic findings on hysterectomy specimens. J Minim Invasive Gynecol 2006;13:325-30.

52. Garuti G, Cellani F, Garzia D, et al. Accuracy of hysteroscopic diagnosis of endometrial hyperplasia: a retrospective study of 323 patients. J Minim Invasive Gynecol 2005;12:247-53.

53. Uno LH, Sugimoto O, Carvalho FM, et al. Morphologic hysteroscopic criteria suggestive of endometrial hyperplasia. Int J Gynaecol Obstet 1995;49:35-40.

54. Loverro G, Bettocchi S, Cormio G, et al. Diagnostic accuracy of hysteroscopy in endometrial hyperplasia. Maturitas 1996;25:187-91.

55. Clark TJ, Voit D, Gupta JK, et al. Accuracy of hysteroscopy in the diagnosis of endometrial cancer and hyperplasia: a systematic quantitative review. JAMA 2002;288:1610-21.

56. Koutlaki N, Dimitraki M, Zervoudis S, et al. Hysteroscopy and endometrial cancer. Diagnosis and influence on prognosis. Gynecol Surg 2010;7:335-41.

57. Committee on Gynecologic Practice, Society of Gynecologic Oncology. The American College of Obstetricians and Gynecologists Committee Opinion no. 631. Endometrial intraepithelial neoplasia. Obstet Gynecol 2015;125:1272-8.

58. Armstrong AJ, Hurd WW, Elguero S, et al. Diagnosis and management of endometrial hyperplasia. J Minim Invasive Gynecol 2012;19:562-71.

59. Raffone A, Travaglino A, Saccone G, et al. PAX2 in endometrial carcinogenesis and in differential diagnosis of endometrial hyperplasia: A systematic review and metaanalysis of diagnostic accuracy. Acta Obstet Gynecol Scand 
2019;98:287-99.

60. Raffone A, Travaglino A, Saccone G, et al. Loss of PTEN expression as diagnostic marker of endometrial precancer: A systematic review and meta-analysis. Acta Obstet Gynecol Scand 2019;98:275-86.

61. Lacey JV Jr, Sherman ME, Rush BB, et al. Absolute risk of endometrial carcinoma during 20-year follow-up among women with endometrial hyperplasia. J Clin Oncol 2010;28:788-92.

62. Morice P, Leary A, Creutzberg C, et al. Endometrial cancer. Lancet 2016;387:1094-108.

63. Terzic $M$, Norton $M$, Terzic S, et al. Fertility preservation in endometrial cancer patients: options, challenges and perspectives. Ecancermedicalscience 2020;14:1030.

64. Yang HP, Cook LS, Weiderpass E, et al. Infertility and incident endometrial cancer risk: a pooled analysis from the epidemiology of endometrial cancer consortium (E2C2). Br J Cancer 2015;112:925-33.

65. Park JY, Kim DY, Kim TJ, et al. Hormonal therapy for women with stage IA endometrial cancer of all grades. Obstet Gynecol 2013;122:7-14.

66. Falcone F, Laurelli G, Losito S, et al. Fertility preserving treatment with hysteroscopic resection followed by progestin therapy in young women with early endometrial cancer. J Gynecol Oncol 2017;28:e2.

67. Mazzon I, Corrado G, Morricone D, et al. Reproductive preservation for treatment of stage IA endometrial cancer in a young woman: hysteroscopic resection. Int J Gynecol Cancer 2005;15:974-8.

68. Zhang Q, Qi G, Kanis MJ, et al. Comparison among fertility-sparing therapies for well differentiated early-stage endometrial carcinoma and complex atypical hyperplasia. Oncotarget 2017;8:57642-53.

69. Mazzon I, Corrado G, Masciullo V, et al. Conservative surgical management of stage IA endometrial carcinoma for fertility preservation. Fertil Steril 2010;93:1286-9.

70. De Marzi P, Bergamini A, Luchini S, et al. Hysteroscopic Resection in Fertility-Sparing Surgery for Atypical Hyperplasia and Endometrial Cancer: Safety and Efficacy. J Minim Invasive Gynecol 2015;22:1178-82.

71. Laurelli G, Di Vagno G, Scaffa C, et al. Conservative treatment of early endometrial cancer: preliminary results of a pilot study. Gynecol Oncol 2011;120:43-6.

72. Casarin J, Bogani G, Serati M, et al. Presence of Glandular Cells at the Preoperative Cervical Cytology and Local Recurrence in Endometrial Cancer. Int J Gynecol Pathol 2020;39:522-8.

73. Erkanli S, Ayhan A. Fertility-sparing therapy in young women with endometrial cancer: 2010 update. Int J Gynecol Cancer 2010;20:1170-87.

74. Giampaolino P, Di Spiezio Sardo A, Mollo A, et al. Hysteroscopic Endometrial Focal Resection followed by Levonorgestrel Intrauterine Device Insertion as a FertilitySparing Treatment of Atypical Endometrial Hyperplasia and Early Endometrial Cancer: A Retrospective Study. J Minim Invasive Gynecol 2019;26:648-56.

75. Gunderson CC, Fader AN, Carson KA, et al. Oncologic and reproductive outcomes with progestin therapy in women with endometrial hyperplasia and grade 1 adenocarcinoma: a systematic review. Gynecol Oncol 2012;125:477-82.

76. Alonso S, Castellanos T, Lapuente F, et al. Hysteroscopic surgery for conservative management in endometrial cancer: a review of the literature. Ecancermedicalscience 2015;9:505.

77. Gallos ID, Yap J, Rajkhowa M, et al. Regression, relapse, and live birth rates with fertility-sparing therapy for endometrial cancer and atypical complex endometrial hyperplasia: a systematic review and metaanalysis. Am J Obstet Gynecol 2012;207:266 e1-12.

78. Tock S, Jadoul P, Squifflet JL, et al. Fertility Sparing Treatment in Patients With Early Stage Endometrial Cancer, Using a Combination of Surgery and GnRH Agonist: A Monocentric Retrospective Study and Review of the Literature. Front Med (Lausanne) 2018;5:240.

79. Pronin SM, Novikova OV, Andreeva JY, et al. FertilitySparing Treatment of Early Endometrial Cancer and Complex Atypical Hyperplasia in Young Women of Childbearing Potential. Int J Gynecol Cancer 2015;25:1010-4.

80. Marshall JC, Dunaif A. Should all women with PCOS be treated for insulin resistance? Fertil Steril 2012;97:18-22.

81. Shan W, Wang C, Zhang Z, et al. Conservative therapy with metformin plus megestrol acetate for endometrial atypical hyperplasia. J Gynecol Oncol 2014;25:214-20.

82. Yang BY, Gulinazi Y, Du Y, et al. Metformin plus Megestrol Acetate (MA) compared with MA alone as fertility-sparing treatment in patients with atypical endometrial hyperplasia and well differentiated endometrial cancer: a randomised controlled trial. BJOG 2020;127:848-57.

83. Gonthier C, Walker F, Luton D, et al. Impact of obesity on the results of fertility-sparing management for atypical hyperplasia and grade 1 endometrial cancer. Gynecol Oncol 2014;133:33-7.

84. Inoue O, Hamatani T, Susumu N, et al. Factors affecting 
pregnancy outcomes in young women treated with fertility-preserving therapy for well-differentiated endometrial cancer or atypical endometrial hyperplasia. Reprod Biol Endocrinol 2016;14:2.

85. Vitale SG, Rossetti D, Tropea A, et al. Fertility sparing surgery for stage IA type I and G2 endometrial cancer in reproductive-aged patients: evidence-based approach and future perspectives. Updates Surg 2017;69:29-34.

86. La Rosa VL, Garzon S, Gullo G, et al. Fertility preservation in women affected by gynaecological cancer: the importance of an integrated gynaecological and psychological approach. Ecancermedicalscience 2020;14:1035.

87. Laganà AS, La Rosa VL, Rapisarda AM, et al. Comment on: "Needs and priorities of women with endometrial and cervical cancer". J Psychosom Obstet Gynaecol 2017;38:85-6.

88. Rodolakis A, Biliatis I, Morice P, et al. European Society of Gynecological Oncology Task Force for Fertility Preservation: Clinical Recommendations for FertilitySparing Management in Young Endometrial Cancer Patients. Int J Gynecol Cancer 2015;25:1258-65.

89. Yang B, Xu Y, Zhu Q, et al. Treatment efficiency of

Cite this article as: Vitale SG, Riemma G, Carugno J, Chiofalo B, Vilos GA, Cianci S, Budak MS, Lasmar BP, Raffone A, Kahramanoglu I. Hysteroscopy in the management of endometrial hyperplasia and cancer in reproductive aged women: new developments and current perspectives. Transl Cancer Res 2020;9(12):7767-7777. doi: 10.21037/tcr-20-2092 comprehensive hysteroscopic evaluation and lesion resection combined with progestin therapy in young women with endometrial atypical hyperplasia and endometrial cancer. Gynecol Oncol 2019;153:55-62.

90. Matsuzaki T, Iwasa T, Kawakita T, et al. Pregnancy outcomes of women who received conservative therapy for endometrial carcinoma or atypical endometrial hyperplasia. Reprod Med Biol 2018;17:325-8.

91. Kudesia R, Singer T, Caputo TA, et al. Reproductive and oncologic outcomes after progestin therapy for endometrial complex atypical hyperplasia or carcinoma. Am J Obstet Gynecol 2014;210:255.e1-4.

92. Corzo C, Barrientos Santillan N, Westin SN, et al. Updates on Conservative Management of Endometrial Cancer. J Minim Invasive Gynecol 2018;25:308-13.

93. Kumar V, Chodankar R, Gupta JK. Endometrial ablation for heavy menstrual bleeding. Womens Health (Lond) 2016;12:45-52.

94. Vilos GA, Edris F, Al-Mubarak A, et al. Hysteroscopic surgery does not adversely affect the long-term prognosis of women with endometrial adenocarcinoma. J Minim Invasive Gynecol 2007;14:205-10. 